\title{
Effect of Zinc Oxide Nanoparticles on the Structure of Testis of Adult Albino Rats and the Possible Protective Role of Naringenin
}

\author{
AMIRA F. A. AHMED, M.Sc.; IBRAHIM A. IBRAHIM, M.D.; HANAN E.L. MOKHTAR, M.D. and \\ MANAL M. MORSY, M.D. \\ The Department of Anatomy \& Embryology, Faculty of Medicine, Zagazig University
}

\begin{abstract}
Background: Zinc oxide ( $\mathrm{ZnO})$ nanoparticles have been used as a source of zinc, in food industry and are applied in cosmetic products, but their accumulation in the tissues causes a hazard toxic effect. Naringenin (Nar) is a member of flavanones groups that play an important role in body health in terms of antioxidant and anti-inflammatory.
\end{abstract}

Aim of Study: The aim of this study is to evaluate the possible structural changes that occur in the testicular tissue of adult albino rat after single injection of zinc oxide nanoparticles and to clarify possible protective role of Naringenin against this toxicity.

Material and Methods: 28 adult male albino rats have been used in this work. These animals were divided into three groups. Group Ia (Control -ve): Animals received no chemicals. Group Ib (control +ve) rats received oral Naringenin $20 \mathrm{mg} / \mathrm{kg}$ once daily for two weeks. Group II (Treated group) received single intraperitoneal injection (IP) of Zno-NPs $(700 \mathrm{mg} / \mathrm{kg}$ ) (as a single toxic dose in the experiment). Group III (Protective group) rats received Zno NPs (as same previous dose and route) in addition to Naringenin $(20 \mathrm{mg} / \mathrm{kg}$ ) orally once daily for 2 weeks. 24 hours after the last administration, rat were sacrificed, carful dissection was performed for gentle removal of both testicles from all groups then processed for light and electron microscopic studies, morphometric examination and statistical analysis. Epididymal sperm was collected for estimation of percentage of sperm Viability and abnormality.

Results: By light microscopy, zinc oxide nanoparticles caused massive histopathological changes in rat testes in the form of disorganization of seminiferous tubules, thickening, detachment and separation of basement membranes, widening of interstitial tissues, thickening and congestion blood vessels and pyknosis of sertoli and germ cells. Ultrastructural results confirmed these histopathological changes and revealed the degeneration of Sertoli cells, all germ cells and interstitial cells as well. The statistical analysis of this study supported the results. Administration of Naringenin to treated group provided mild improvement to the testicular tissues against Zno-NPs toxicity.

Correspondence to: Dr. Amira F.A. Ahmed, E-Mail: amiraahmed 149@yahoo.com
Conclusion: Zinc oxide nanoparticles could result in hazards to the structure of testes. Fortunately co-administration of Naringenin is suggested to reduce such hazards.

Key Words: Adult albino rats - Testes - Zinc oxide nanoparticles - Naringenin.

\section{Introduction}

NANOPARTICLES (NPs) are ultrafine units with dimensions measured in nanometres $(\mathrm{nm} ; 1 \mathrm{~nm}=$ $10^{-9}$ metre) and their lengths are ranging from 1$1000 \mathrm{~nm}$ in at least at one of their dimension [1] The importance of NPs materials was focused when researcher detected that the nano size of particles can influence their physiochemical properties. Nanoparticles can penetrate the cell membrane and biological barriers efficiently when compared to micro-sized particles [2,3]. Despite of numerous medical and industrial applications, there are deficient in information and clarifications concerning the assessment of true risk of Nanoparticles on environment and human health [4,5]

Zinc oxide nanoparticles (ZnO-NPs) are one of the common popular widely used materials in cosmetics products such as sunscreen and personal care. Recently, ZnO-NPs have attracted great attention to enhance the uptake of zinc. The cytotoxic and genotoxic potential of $\mathrm{ZnO}-\mathrm{NPs}$ have been reported using in vitro assays in lung epithelial, immune cells and cancer cells [6]. Concerning the potential toxic effect of $\mathrm{ZnO}-\mathrm{NPs}$ on male reproduction field is possible, so further insights are needed to clarify this issue.

Naringenin is one of the members of flavanones and has a role in body health in terms of antiinflammatory and antioxidant. The antioxidant activityof naringenin depend mainly on its ability to bind to deoxyribonucleic acid (DNA). Also 
cytotoxic activities of naringenin to cancer cells was reported [7]. Citrus fruits, especially Grapefruit are considered as the mean source of naringenin. One-half mandarin and one-half orange can provide at least $30 \mathrm{mg}$ of naringenin $[8,9]$.

Little studies are existed on the changes that can be induced by $\mathrm{ZnO}-\mathrm{NPs}$ on the rat testicular tissue. Furthermore, to our knowledge, no previous ultrastructural studies showed this effect. So, the present work was performed to determine $\mathrm{ZnO}$ NPs effect on testicular structure and the possible ameliorating role of naringenin.

\section{Patients and Methods}

1- Chemicals:

1- Zinc oxide nanoparticles ( $\mathrm{ZnO}-\mathrm{NPs}$ ) are white fine powder purchased in bottles from Sigma Chemical Company, Egypt (Eltayaran St., Nasr city, Cairo). Each bottle contains $5 \mathrm{gm}$ with particle size $<50 \mathrm{~nm}$ and CAS No. was 677450.

2- Naringenin is a white powder purchased from Sigma, Egypt (Eltayaran St., Nasr city, Cairo) in bottles, each bottle contains $1 \mathrm{gm}$ and CAS No. Was N5893.

Dosage preparation: The $\mathrm{ZnO}-\mathrm{NPs}$ powder was suspended in normal distilled water and then dispersed by vortexing for one minute using shaker's apparatus to prepare a stock solution with a concentration of $500 \mathrm{mg} \mathrm{ZnO}-\mathrm{NPs} / \mathrm{mL}$ distilled water ( $\mathrm{pH}$ was 7.3). Then the required dose of $\mathrm{ZnO}-\mathrm{NPs}$ was prepared with a concentration of $700 \mathrm{mg} / \mathrm{mL}$ distilled water [10]. This preparation was done in the animal house, faculty of medicine, Zagazig University during 2018.

\section{2- Animals and experimental design:}

Twenty eight healthy adult male Wistar albino rats (about 4-month old and their weights range from 150 to $160 \mathrm{~g}$ ), obtained from the animal house, Faculty of Medicine, Zagazig University were included in this study. Rats were housed in well controlled temperature and light and allowed to feed on standard food and water ad-libitum. All experiments were carried out in accordance with the guidelines of Ethical Committee of the Institutional Animal Care, Zagazig University. The rats were divided into 3 groups as follow:

A- Control group (I): this group contained 14 rats and was further subdivided into 2 equal subgroups as follow:

1- Subgroup Ia: (negative control): 7 rats did not received any treatment but were received balanced diet.
2- Subgroup Ib: (Positive control): 7 rats received oral Naringenin $20 \mathrm{mg} / \mathrm{kg}$ once daily for two weeks [11]

$B$ - The treated group (II): 7 rats received single IP injection of high toxic dose of Zno-NPs (700mg/ $\mathrm{kg}$ dispersed in distilled water).

$C$ - The protective group (III): 7 rats received single IP injection of $700 \mathrm{mg} / \mathrm{kg}$ Zno-NPs in addition to $20 \mathrm{mg} / \mathrm{kg}$ Naringenin administrated orally once daily for 2 weeks.

The body weights of all rats of all studied groups were estimated at the begining of the experiment before administration of food and drugs (as initial body weight) and at the end of the experiment before sacrificing the animals (as a final body weight) using the same sensitive digital balance. These recorded data were collected for statistical analysis.

By the end of the experiment (after 2 weeks), all animals were sacrificed by decapitation. Both testes from each animal were immediately dissected carefully, removed out and washed with cold normal saline. Then the specimens were processed to be evaluated by the following.

\section{I- Histological study:}

1-Light microscopic examination: Testis Samples were fixed in $10 \%$ buffered neutral formalin then processed by using the common standard procedure for obtaining paraffin blocks. Serial 5 $\mathrm{gm}$ thick sections were stained with hematoxylin and eosin [12].

2- Electron microscopic examination: The specimens were cut into very small pieces $1-3 \mathrm{~mm}^{3}$ in dimensions by sharp razors on a sheet of dental wax. The specimens were fixed in buffered glutaraldehyde solution, in $1 \%$ osmium tetroxide, and embedded in epoxy resin after being dehydrated. The specimens then processed by using the common standard procedure for obtaining semi and ultrathin sections using Leica Ultracut (UCT) with glass knives [13]. The semithin sections $(0.8 \mathrm{gm})$ were mounted in adrop of water on glass slides and stained with Toluidine blue [14] for light microscope examination. However, the ultrathin sections (60$70 \mathrm{~nm}$ thick) were examined under transmission electron microscope (JEOL-TEM-2100), in Electron Microscope Research Laboratory (EMRL), Faculty of Agriculture, Mansoura University.

\section{II- Morphometric analysis:}

Sections stained with $\mathrm{Hx} \&$ Eper 100 high power fields were morphometically analyzed. Data were 
obtained using computerized image's analyzer (Leica Imaging System Ltd., Cambridge, England) at Anatomy and Embryology Department, Faculty of Medicine, Zagazig University.

The following measurements were calculated using the interactive measure menu:

1- The mean seminiferous tubular perimeter (STP)/ unit area Fig. (A).

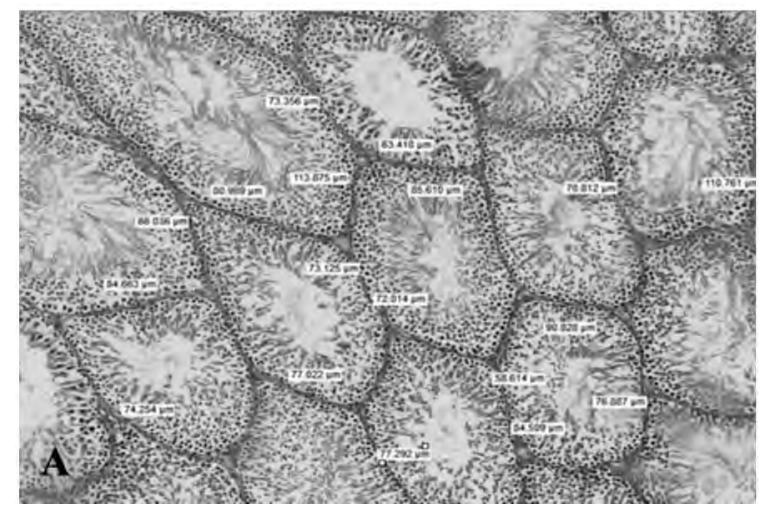

2- The mean seminiferous epithelial height (SEH)/ unit area Fig. (B) (Unit area=microscopic field) as mentioned before by Bartra et al., [15] .

Six non-overlapping fields from six rat testis sections were selected randomly and were recorded. For each specimen, the mean values and standard deviations automatically were calculated using computerized image's analyzer.

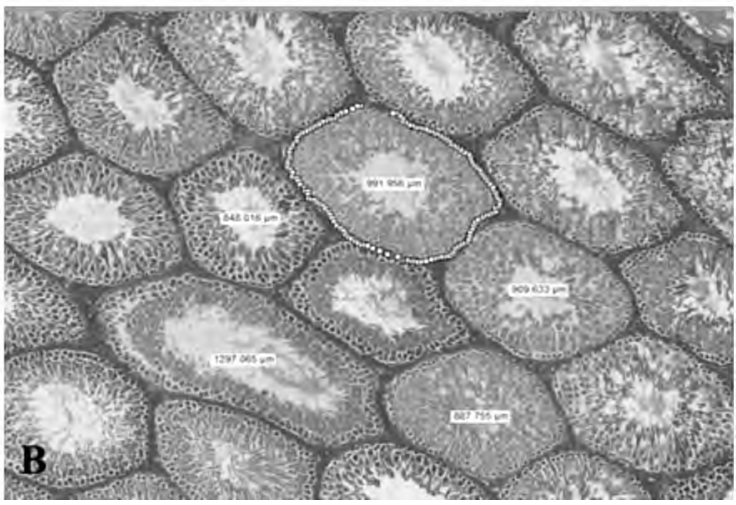

Fig. (A,B): A photomicrograph of a copy of monitor's screen of image analyzer from a section of adult albino rat testis (A): Showing the method of measuring the mean seminiferous epithelial height (SEH)/unit area in the field. (B): showing the method of measuring the mean seminiferous tubular perimeter (STP)/ unit area in the field (lined by red marker). (H\&E x100)

\section{III- Epididymal spermatozoal examination:}

Epididymal sperm content of each rat was obtained immediately after cutting the tail of epididymis to squeeze it gently to discharge its sperm content in a clean Petri dish as described before by Klinefelter et al., [16] to estimate the following:

\section{1- Epididymal sperm viability:}

A drop of Epididymal sperm content of each rat was mixed with an equal drop of eosin-nigrosin stain. The fluid was carefully mixed with the stain. These films were spread on clean and grease free slides. The data was collected under high power lens of light microscope. The number of dead (stained) and live (unstained) sperms were estimated among the two hundred sperms. Then the percentage of sperms' motility/unit area was calculated and analyzed statistically [17].

\section{2- Sperm abnormality:}

The data was collected to calculate the percentage of abnormal forms of sperms/unit area then analyzed statistically as previously described by Mori et al., [18]

\section{VI- Statistical analysis:}

The collected data were computerized and statistically analyzed using SPSS version 18.0 for windows program (Statistical Package for Social
Science). The quantitative data were expressed as mean \pm SD (Standard deviation). All statistical comparisons were two-tailed. Paired-samples $t$ test (dependent $t$-test): Was used to determine significant difference between initial and final body weight of each group. A one-way ANOVA: Was used to detect statistical differences between groups followed by post hoc least significance difference (LSD) test for multiple comparisons between groups. Difference was considered significant at $p<0.05$.

\section{Results}

\section{I- Histological examination:}

\section{A- Light microscopic examination:}

\section{1- Hematoxylin and eosin stain:}

Hematoxylin and eosin stained sections from the control group showed normal structure of testicular parenchyma that was composed of oval to round closely packed seminiferous tubules and little interstitial tissues (Fig. 1a). Each tubule was lined by a seminiferous stratified germinal epithelium and Sertoli cells. The stratified epithelium was composed of well arranged layer of cells; spermatogonia, primary and secondary spermatocytes, then spermatids and lastly spermatozoa from outward inward. The spermatogonia were small cells resting on the basement membrane and have 
characteristic dark nuclei. The primary spermatocytes appeared as largest cells situated above spermatogonia and had large nuclei that contained splitted chromatin. Rounded (early) and elongated (late) spermatids were found near lumen which contained several spermatozoa. The interstitial tissues were observed in between tubules containing Leydig cells and blood vessels (Fig. 1b).

However, the $\mathrm{ZnO}$-NPs treated group revealed massive degenerative testicular changes if compared with control groups. Disorganization of seminiferous tubules with irregular corrugated outline or detached and separated basement membranes were observed. Very wide interstitial tissues with thick walled congested blood vessels were seen (Fig. 1 c). Extensive acidophilic hyaline material in the interstitium with presence of lipid droplets and dark stained pyknotic leydig cells were seen. The neighboring tubule showed decrease thickness of the germinal layer (Fig. 1d). Sloughing or depletion of germinal epithelium was also seen. Some spermatogenic cells appeared pyknotic and surrounded by spaces. The cavity of some tubules showed no sperms (Fig. 1e,f).

The Zno-NPs and Nar treated group revealed mild improvement. There is well organization of seminiferous tubules as they were packed together and retained their regular outline. However, slight widening of interstitium was still seen. Most of the tubules have normal stratification of germinal epithelium with considerable sperms in their lumens however slight sloughing of germinal epithelium from basement membrane was still observed. Few lipid droplets were present in the interstitium (Fig. $1 \mathrm{~g}, \mathrm{~h})$.

\section{2- Toluidine blue stain:}

Semithin sections of normal (control) adult rat testis stained by Toluidine blue showed seminiferous tubules surrounded by basal lamina with normally distributed germ cells. The spermatogonia were located above basal lamina, however, the primary spermatocytes were the largest and lying above spermatogonia. There were many layers of early spermatids which appeared smaller and above the primary spermatocytes. Sertoli cells were resting on basement membrane. Interstitial tissue was observed containing several leydig cells (2a). ZnO-NPs treated group showed multiple degenerated spermatogenic cells with darkly stained pyknotic nuclei. Marked spaces were seen among spermatogenic cells (2b). ZnO-NPs + Nar treated group revealed normal seminiferous tubule lined by spermatogonia, primary spermatocytes and spermatids. Sertoli cell with a large oval nucleus was seen resting on basement membrane. Some few spaces were still present between spermatogenic cells $(2 \mathrm{c})$.

\section{B- Electron Microscopic Finding:}

\section{1-Sertoli cell:}

In the normal (control) rat testis, the sertoli cells showed intended euchromatic nucleus and prominent nucleolus, multiple round mitochondria, rough endoplasmic reticulum, and few lysosomes. The basement membrane was ensheathed by myoid cell (Fig. 3a). In the ZnO-NPs treated testicular sections, the sertoli cells appeared with electron dense nucleus, dilated smooth and rough endoplasmic reticula, few distorted mitochondria, large intracytoplasmic vacuoles and large lipid droplets. Thickening of basement membrane and wide intercellular spaces were also seen (Fig. 3b,c). However in the ZnO-NPs and Naringenin treated group, the sertoli cells exhibited large intended nuclei with prominent nucleoli and multiple mitochondria. Some small intracytoplasmic vacuoles were still present (Fig. 3d).

\section{2- Spermatogonia:}

Spermatogonia of normal (control) rat testis were applied to the basement membrane. They contained rounded nuclei with dense clumps of peripheral heterochromatin and ovoid mitochondria. The tight junctions between the cells were seen (Fig. 4a). In the Zno-NPs treated group, spermatogonia were resting on basement membrane and contained shrunken heterochromatic nuclei with irregular outlines. Some cells appeared with disintegrated nuclei leaving remains of clumps of chromatin through their rarified cytoplasm with massive loss of most organelles (Fig. 4b). In the Zno-NPs and Naringenin treated group, the spermatogonia showed ovoid nucleus with less dense clumps of peripheral heterochromatin. They rested on well defined basement membrane (Fig. 4c).

\section{3- Primary spermatocyte:}

The primary spermatocyte (Ps) of normal rat testis had large rounded nuclei with fine electron dense irregular clumps of heterochromatin. Their cytoplasm exhibited aggregated number of small vacuolated mitochondria (Fig. 5a). The ZnO-NPs treated testicular sections showed that Ps containing few aggregated mitochondria, ovoid shrinked nuclei with electron dense chromatic clumps and disintegrated nuclear membranes (Fig. 5b,c). In the $\mathrm{ZnO}-$ NPs and Naringenin treated group revealed that PS with large oval nucleus and some fine electron dense clumps of heterochromatin. Their cytoplasm 
had number of small aggregated mitochondria (Fig. $5 d)$.

\section{4- Spermatids:}

The normal rat testis showing the spermatid cells with well defined euchromatic nuclei surrounded by distinct nuclear membrane. The acrosomal cap appeared spreading over the anterior hemisphere of their nuclei. The cytoplasm showed vacuolated peripheral mitochondria. The tight junction between cells was seen (Fig. 6a). The $\mathrm{ZnO}$-NPs treated testicular sections showed groups of Spermatids having electron dense shrunken nuclei with multiple wide spaces between the cells. Electron dense or electron lucent vacuoles were seen inside their cytoplasm (Fig. 6b,c). The $\mathrm{ZnO}$ NPs and Naringenin treated testicular sections showed some spermatids with normal acrosomal cap or with normal Golgi vesicle and peripheral mitochondria. Other spermatids showed abnormal acrosomal cap or with centrally- sited mitochondria or with many lysosomes in their cytoplasm (Fig. $6 d)$.

\section{5- The spermatozoa:}

The middle pieces of the sperm of normal rat testis displayed core of central axoneme surrounded by nine electron dense fibers and outer less dense mitochondrial sheath. However, the principal pieces were formed of axoneme surrounded by seven outer dense fibers and enclosed by fibrous sheath. Terminal end pieces were formed of axoneme surrounded by a cell membrane (Fig. 7a). The ZnO-NPs treated testicular sections showed swelling and vacuolation of mitochondrial sheath of middle pieces of the sperms (Fig. 7b). Distorted middle piece of sperms with invisible hazy central part were observed. The terminal end pieces are markedly degenerated and disorganized (Fig. 7c). The ZnO-NPs and Nar treated testicular sections showed normal middle pieces of the sperms consisting of core of central axoneme surrounded by nine outer dense fibers, mitochondrial sheath. Some of sperm pieces still appeared deformed and degenerated (Fig. 7d).

\section{6- Leydig cells:}

The Leydig cells of normal rat testis appeared with large rounded euchromatic nuclei and thin marginated chromatin. Its cytoplasm contains moderate number of mitochondria of variable size and density and extensive cytoplasmic processes interdigitating with the neighboring ones (Fig. 8a). The ZnO-NPs treated testicular section showed shrinked Leydig cells. It had highly indented nucleus with condensed marginated chromatin. It contained many variable-sized electron dense mitochondria (Fig. 8b). However, The ZnO-NPs and Nar treated testicular sections showed Leydig cells with large rounded euchromatic nuclei with thin marginated chromatin and few peripheral spots of chromatin. It contained moderate number of mitochondria of variable size and shape (Fig. 8c).

\section{II- Epididymal spermatozoal examination:}

Staining spermatozoa with Eosin-Nigrosin revealed the structure of normal sperm with hocked heads, neck and tail connected to each other (Fig. 9a). The Staining spermatozoa of ZnO-NPs treated group showed Abnormal forms present in different percentage. The abnormal forms of sperm were in the form of Sperm with banana head, with coiled midpiece, with curved tail, with short tail and with kinked neck as shown in (Fig. 9b-f).

\section{III- Statistical results:}

A-Statistical analysis of rat body weights $(B W)$ : (Table 1).

1- No statistically significant differences in the mean of initial body weights of animals were noted $(p>0.05)$. However, there were highly statistical significant differences in the mean of final body weights of animals in all groups were noted $\left(p^{<} \_0.001\right)$.

2- The final body weights of ZO-NPs treated group were highly significantly decreased as compared to their initial body weights of same group or to the final body weight of control group $\left(p^{<}\right.$ 0.001 ).

3- The final body weights of ZO-NPs + Naringin treated groups was highly significantly increased as compared with final body weight of ZO-NPs treated group $\left(p^{\prec} \_0.001\right)$.

\section{B- Statistical analysis of morphometric measure-} ments:

\section{1- Statistical analysis of Perimeter of seminiferous} tubules:

There was high significant decrease in the mean values of the perimeter of seminiferous tubules in the treated group II $(p<0.001)$ if compared with control groups. By treatment with Naringinin, these values were highly significantly increased in the protected groups (III) if compared with treated groups (II) $(p<0.001)$ (Table 2).

\section{2- Statistical analysis of height of germinal epithe- lial layer:}

There was high statistical significant decrease in the mean values of height of germinal epithelial layer in the treated group (II) $(p<0.001)$ if compared 
with control groups. However, by treatment with Naringinin, these values were significantly increased in the protected group (III) if compared with the treated groups (II) $(p<0.0176 *)$ (Table 2).

\section{C- Statistical sperm analysis:}

There were highly significant decrease in percentage (\%) of sperms' motility in the groups treated by Zn-NPs (II) if compared with control groups $(p<0.001)$, however, the percentage of abnormal sperm forms was highly significantly increased $(p<0.001)$. By treatment with Naringinin, there were highly significant increased in percentage $(\%)$ of sperms' motility in the protected groups (III) if compared with treated groups (II) $(p<0.001)$, however, the percentage of abnormal sperm forms was highly significantly decreased $(p<0.001)$ (Table $3)$.

Table (1): Statistical analysis of Initial and Final body weight (BW) of experimental adult albino rats by using A one-way ANOVA followed by post hoc least significance difference (LSD) test for multiple comparisons between groups.

\begin{tabular}{|c|c|c|c|c|}
\hline \multirow{2}{*}{ Groups } & \multicolumn{2}{|c|}{ Body weight (BW) } & \multirow{2}{*}{$\begin{array}{c}\text { Paired } \\
t \text {-test }\end{array}$} & \multirow{2}{*}{$\begin{array}{c}p- \\
\text { value }\end{array}$} \\
\hline & Initial BW & Final BW & & \\
\hline $\begin{array}{l}\text { Negative control (Ia group): } \\
\text { Mean } \pm \text { SD }\end{array}$ & $218 \pm 4.2$ & $222 \pm 7.7$ & $t=1.4$ & $\leq 0.23$ \\
\hline $\begin{array}{l}\text { Positive control (Ib group): } \\
\text { Mean } \pm \text { SD }\end{array}$ & $220 \pm 6.2$ & $250 \pm 8.6 \mathbf{a}$ & $t=6.7$ & $\leq 0.006$ \\
\hline $\begin{array}{l}700 \text { ZO-NPs treated group (II group): } \\
\text { Mean } \pm \text { SD }\end{array}$ & $214 \pm 9.7$ & $181 \pm 5.4 \mathbf{a b}$ & $t=7.9$ & $\leq 0.001$ \\
\hline $\begin{array}{l}700 \mathrm{ZO}-N P s+\text { Naringin (III group): } \\
\text { Mean } \pm \mathrm{SD}\end{array}$ & $211 \pm 10.2$ & $190 \pm 9$ abc & $t=3.4$ & $\leq 0.014$ \\
\hline ANOVA & $\mathrm{F}=0.84$ & $\mathrm{~F}=62.7$ & & \\
\hline$p$-value & $\leq 0.53$ & $\leq 0.001$ & & \\
\hline
\end{tabular}

$\mathrm{n}=7$ rats per group. $\quad$ ZO-NPs $=$ Zinc oxide nanoparticles.

a: Significant vs negative control group.

b: Significant vs positive control group.

c: Significant vs 700-ZO-NPs treated group, $(p<0.05)$ within the column.

Table (2): Statistical analysis of Perimeter of seminiferous tubules ( $m$ )and height of the germinal epithelium of experimental adult albino rat testis by using one-way ANOVA test.

\begin{tabular}{|c|c|c|c|c|c|c|}
\hline \multirow[t]{2}{*}{ Parameter } & $\begin{array}{c}\text { Group } \\
\text { Ia (-ve control) }\end{array}$ & $\begin{array}{c}\text { Group } \\
\text { Ib (+ve control) }\end{array}$ & $\begin{array}{c}\text { Group } \\
\text { II (700 } \\
\text { ZnO-NPs) }\end{array}$ & $\begin{array}{c}\text { Group } \\
\text { III (700 ZnO- } \\
\text { NPs+Nar) } \\
\end{array}$ & $\mathrm{F}$ & $p$ \\
\hline & Mean \pm SD & Mean \pm SD & Mean \pm SD & Mean \pm SD & & \\
\hline $\begin{array}{l}\text { Perimeter of seminiferous } \\
\text { tubules }(\mathrm{m})\end{array}$ & $\begin{array}{l}933.3 \\
\pm 61.1\end{array}$ & $\begin{array}{l}935.4 \\
\pm 110.6\end{array}$ & $\begin{array}{l}689.4^{\mathbf{a b}} \\
\pm 56.4\end{array}$ & $\begin{array}{l}749.4 \text { abc } \\
\pm 34.96\end{array}$ & 25.01 & $<0.001 * *$ \\
\hline $\begin{array}{l}\text { Height of the germinal } \\
\text { epithelium }(\mathrm{m})\end{array}$ & $\begin{array}{l}62.4 \\
\pm 10.9\end{array}$ & $\begin{array}{l}62.6 \\
\pm 18.7\end{array}$ & $\begin{array}{l}28.9^{\mathbf{a b}} \\
\pm 4.3\end{array}$ & $\begin{array}{l}47.6^{\mathbf{a b c}} \\
\pm 13.5\end{array}$ & 13.4 & $<0.001 * *$ \\
\hline
\end{tabular}

Table (3): Statistical analysis of percentages of sperm motility and abnormal sperm forms of experimental adult albino rat testis by using A one-way ANOVA test followed by post hoc least significance difference (LSD) test.

\begin{tabular}{|c|c|c|c|c|c|c|}
\hline \multirow[t]{2}{*}{ Variables } & $\begin{array}{l}\text { Negative } \\
\text { control }\end{array}$ & $\begin{array}{l}\text { Positive } \\
\text { control }\end{array}$ & $700 \mathrm{ZnO}-\mathrm{NPs}$ & $\begin{array}{c}700 \text { ZnO-NPs+ } \\
\text { Naringenin } \\
\end{array}$ & \multirow[t]{2}{*}{ ANOVA } & \multirow[t]{2}{*}{$\begin{array}{c}p- \\
\text { value }\end{array}$} \\
\hline & Mean \pm SD & Mean \pm SD & Mean \pm SD & Mean \pm SD & & \\
\hline Sperm Motility (\%) & $86 \pm 9.8$ & $90 \pm 8.2$ & $20 \pm 5.6^{\mathbf{a b}}$ & $40 \pm 5.6^{\mathbf{a b c}}$ & $\mathrm{F}=63.9$ & $<0.001$ \\
\hline $\begin{array}{l}\text { Abnormal } \\
\text { forms of Sperm (\%) }\end{array}$ & $9 \pm 3.4$ & $8 \pm 3.8$ & $70 \pm 11 \mathbf{a b}$ & $50 \pm 14.1$ abc & $\mathrm{F}=54.4$ & $<0.001$ \\
\hline
\end{tabular}

$\mathrm{n}=7$ rats per group

ZnNPs=Zinc oxide nanoparticles

a: Significant vs negative control group.

b: Significant vs positive control.

c: Significant vs $700 \mathrm{ZnO}-\mathrm{NPs},(p<.05)$ within the row. 

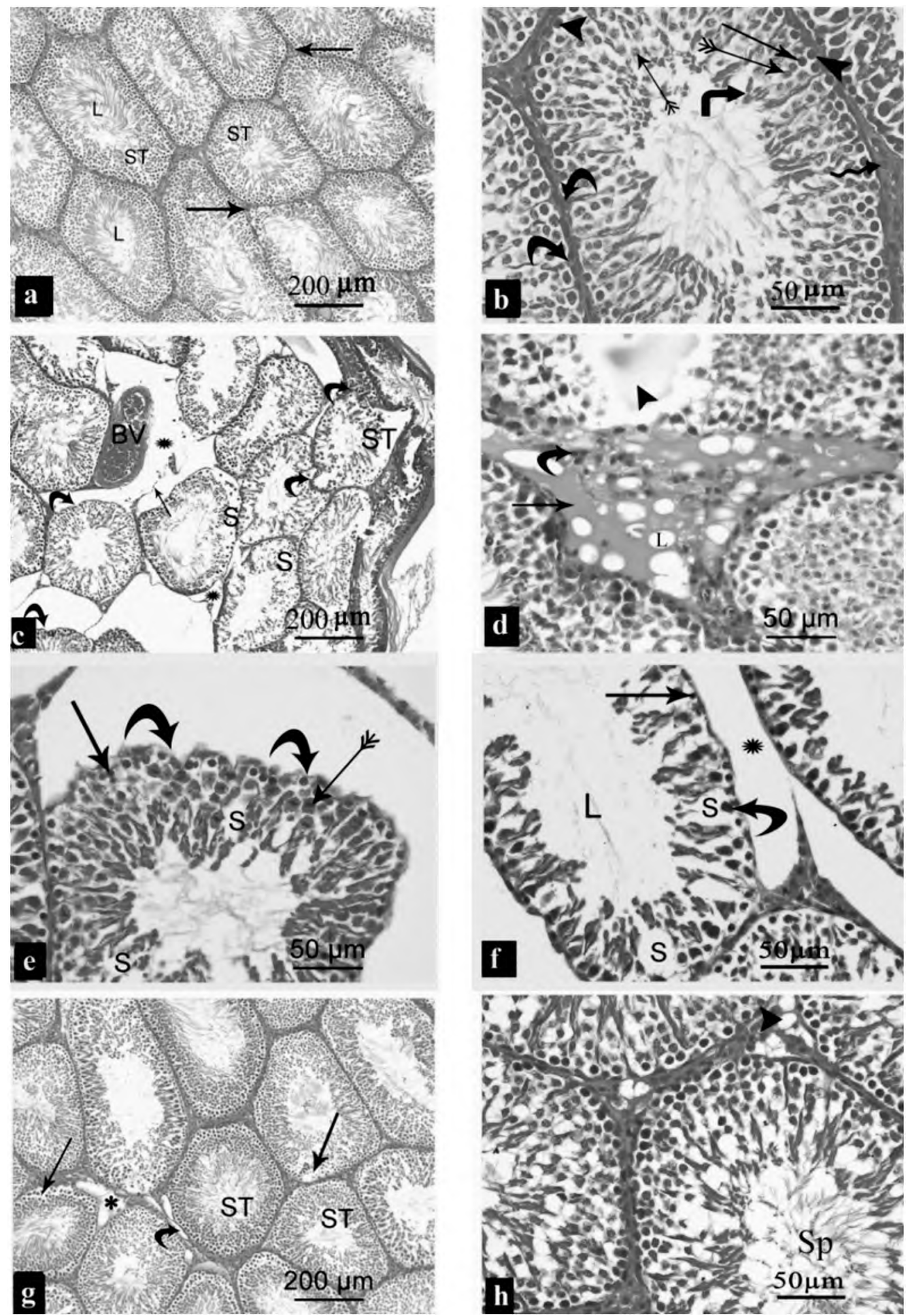

Fig (1. A-H): A photomicrograph of sections of adult albino rat testis. (A-B): Showing sections of normal (control) testis. (A): Showing closely packed seminiferous tubules (ST) with their lumens (L) filled with sperms. Little interstitial tissues (arrow) are observed. (H\&E x 100) (B): Showing seminiferous tubules lined by Sertoli cells (curved arrow) and different germ cells namely, spermatogonia (arrow head), primary spermatocyte (arrow) spermatids (bifid arrows) and spermatozoa (bent arrow) from outward inward. The interstitial tissues (zigzag arrow) contain Leydig cells and blood vessels. (H\&E x400) (C-F): Showing 700mg ZnO-NPs treated testicular sections. (C): Showing disorganized seminiferous tubules (ST) with irregular corrugated outline (curved arrow) or with detached and separated basement membranes (arrow). Very wide interstitial tissues $(*)$ and thick walled congested blood vessels (BV) are observed (H\&E x100) (D): Showing extensive acidophilic hyaline material (arrow) in the interstitium with presence of lipid droplets (L) and darkly stained pyknotic leydig cells (curved arrow). The neighboring tubule shows with decrease thickness of the germinal layer (arrow head) (H\&E x 400). (E-F): SHowing sloughing of germinal epithelium with irregular outlines (curved arrow). The spermatogonia (arrow) and spermatocyte (bifid arrow) appear with darkly stained nuclei. Spermatogenic cells appear surrounded by spaces (S). The lumen of the tubule (L) shows no sperms. (H\&E x 400) (G-H): Showing 700mg ZnO-NPs + Naringenin treated testicular sections. (G): Showing well organized seminiferous tubules (ST) with regular outline. Slight sloughing of germinal epithelium (curved arrow) and widening of interstitium $(*)$ are seen. (H\&E x100) (H): Showing normal stratification of germinal epithelium lining the tubules with considerable sperms (Sp) in their lumens. Few lipid droplets (arrowhead) are present in the interstitium. (H\&E x 400). 

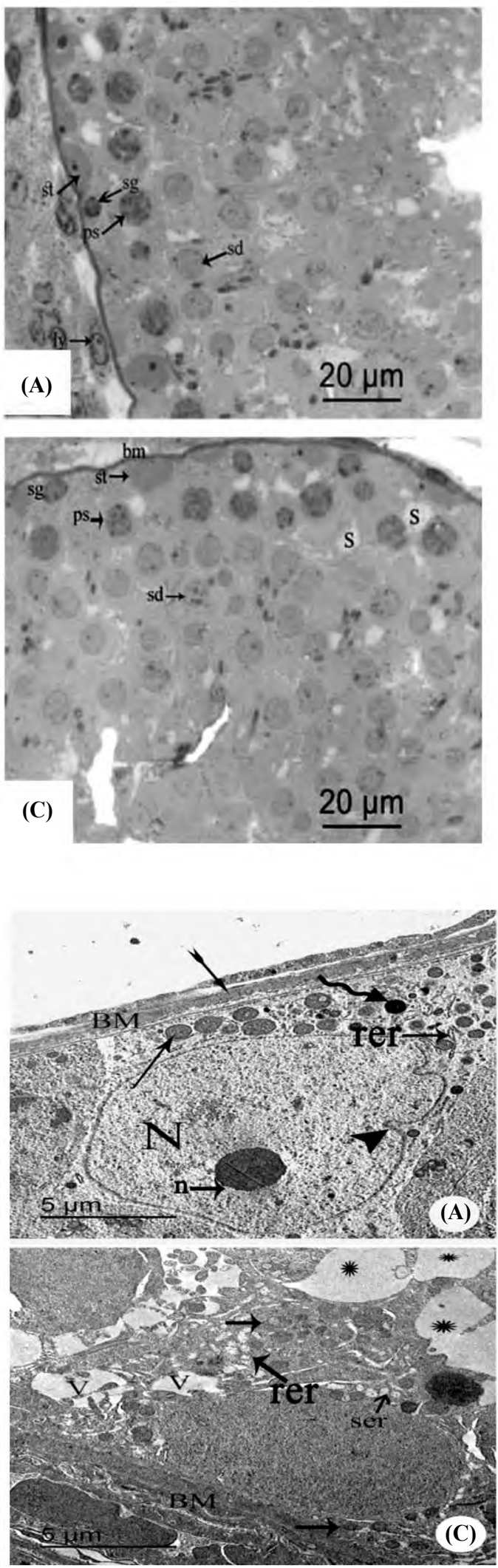

Fig. (3A-D): An electron micrograph of sections of adult albino rat testis. (A): The normal rat testis showing sertoli cell with intended (arrow head) euchromatic nucleus $(\mathrm{N})$ and prominent nucleolus (n), multiple round mitochondria (arrow), rough endoplasmic reticulum (rer) and few lysosomes (zigzag arrow). The basement membrane (BM) is ensheathed by myoid cell (notched arrow). (B,C): The ZnO-NPs treated testicular sections showing sertoli cells containing electron dense nucleus $(\mathrm{N})$, dilated smooth (curved arrow) and rough (rer) endoplasmic reticula and few distorted mitochondria (arrow) and large lipid droplets (ld). Notice the large intracytoplasmic vacuoles (V), the widening of intercellular spaces (*) and thickening of basement membrane (BM) are also seen. (D): The ZnO-NPs+Nar treated testicular sections showing sertoli cell having large intended nucleus $(\mathrm{N})$ with prominent nucleolus (n), and multiple mitochondria (arrow). Some small intracytoplasmic vacuoles $(\mathrm{V})$ are still present. (TEM x1000x17).

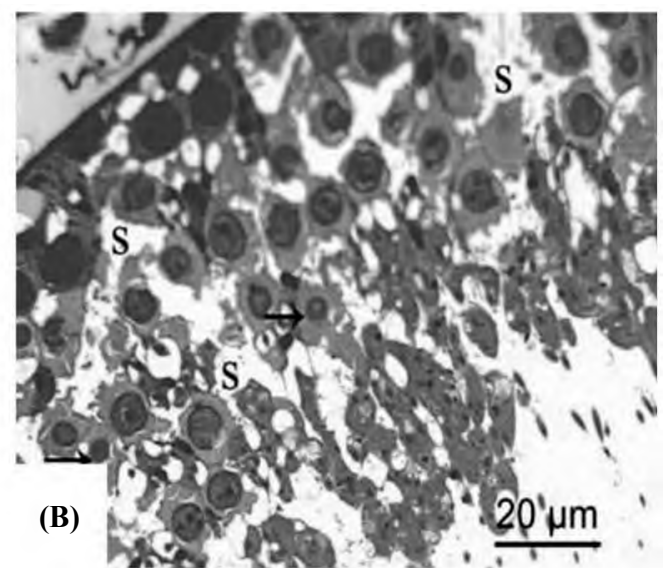

Fig. (2. A-C): A Photomicrograph of semithin sections from adult rat testis. (A): sections of normal (control) testis showing the normal spermatogonic cells; spermatogonia (sg), primary spermatocytes (ps) \& spermatids (sd). Sertoli cells (st) are resting on basement membrane. Interstitial tissue with several leydig cells (ly) is observed. (B): $\mathrm{ZnO}-\mathrm{NPs}$ treated group showing multiple degenerated spermatogenic cells with darkly stained pyknotic nuclei (arrow). Marked spaces (s) among spermatogenic cells are seen. (C): ZnO-NPs + Nar treated group showing a seminiferous tubule lined by spermatogonia (sg), primary spermatocytes (ps) \& spermatids (sd). Sertoli cell (st) with a large oval nucleus is seen resting on basement membrane (bm). Some few spaces (s) are still present between spermatogenic cells. (Toluidine blue x 1000).
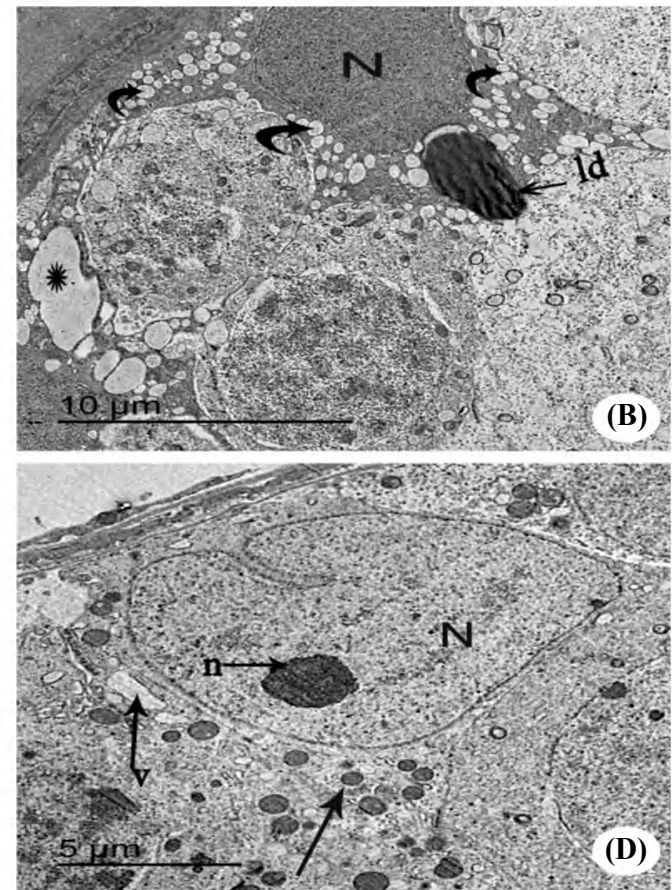

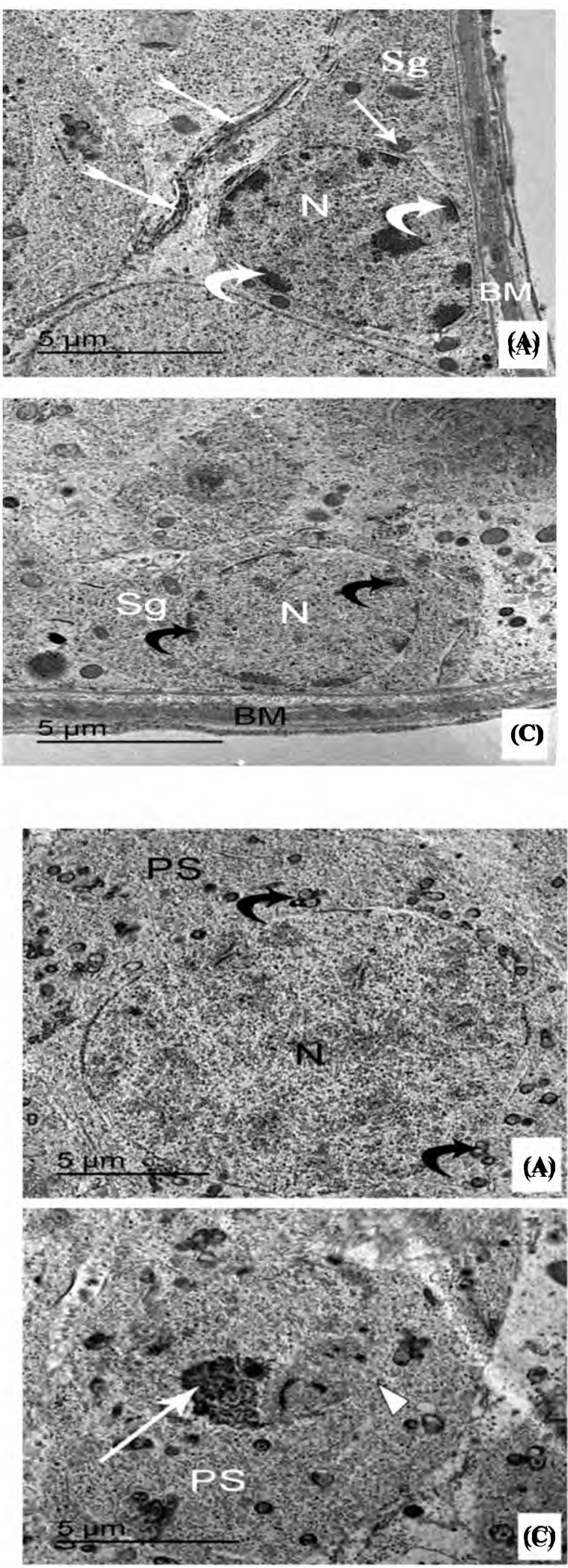

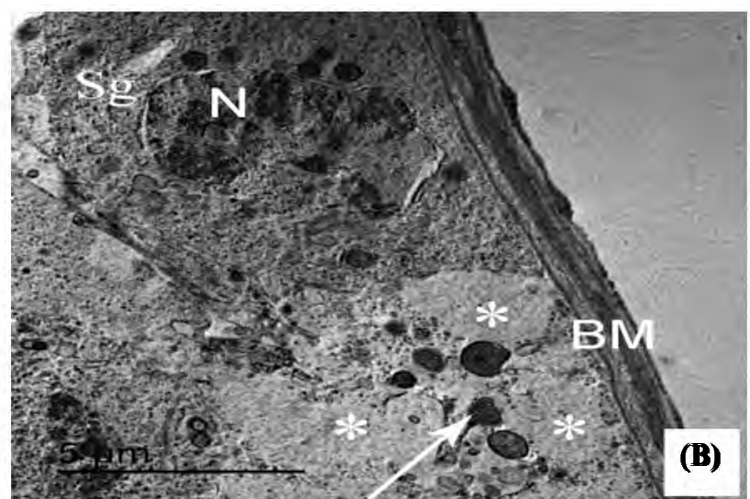

Fig. (4A-C): An electron micrograph of sections of adult albino rat testis showing spermatogonia $(\mathrm{Sg})$. (A): Showing spermatogonia ( $\mathrm{Sg}$ ) of normal (control) rat testis applied to the basement membrane (BM). They contain rounded nuclei $(\mathrm{N})$ with dense clumps of peripheral heterochromatin (curved arrow) and ovoid mitochondria (arrow). Notice the tight junction between the cells (notched arrow) is seen. (B): The $\mathrm{ZnO}-\mathrm{NPs}$ treated testicular section showing spermatogonia ( $\mathrm{Sg}$ ) resting on basement membrane (BM) and contains shrunken heterochromatic nucleus (N) with irregular outline. Some cells appear with disintegrated nucleus leaving remains of clumps of chromatin (arrow) through the rarified cytoplasm (*). (C): The ZnO-NPs and Nar treated testicular sections showing spermatogonia $(\mathrm{Sg})$ with ovoid nucleus (N) containing less dense clumps of peripheral heterochromatin (curved arrow). It rests on well defined basement membrane (BM). (TEM x 1200x17).
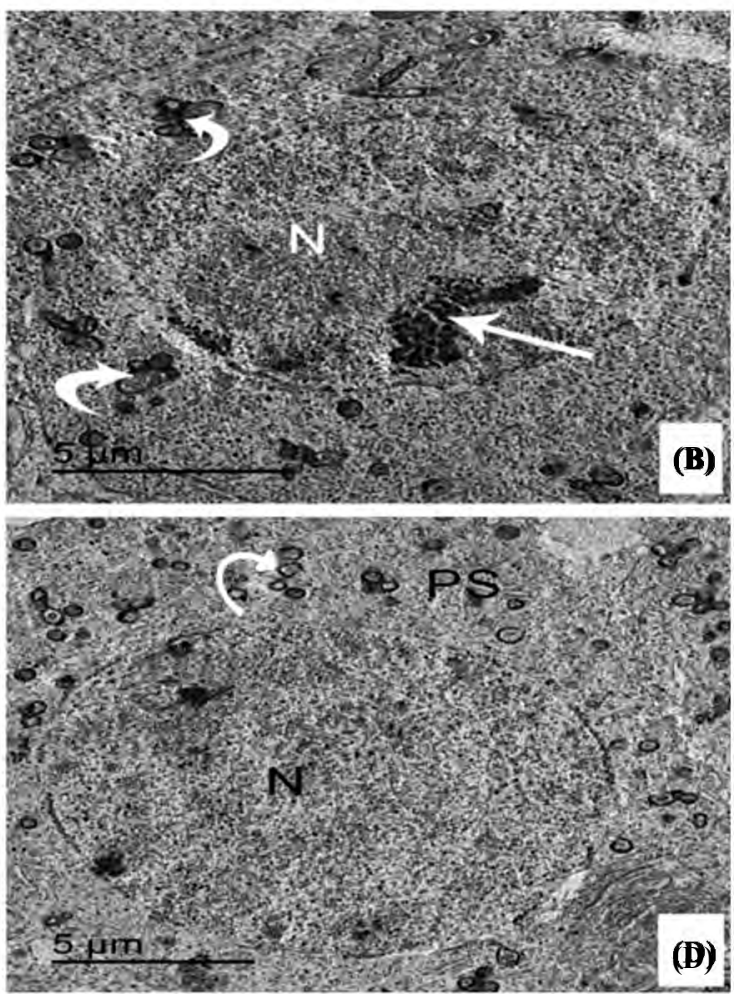

Fig. (5A-D): An electron micrograph of sections of adult albino rat testis showing the primary spermatocytes (PS). (A): The primary spermatocyte (Ps) of normal (control) rat testis have large rounded nuclei $(\mathrm{N})$ with fine electron dense, irregular clumps of heterochromatin (arrow). Their cytoplasm exhibits aggregated number of small vacuolated mitochondria (curved arrow). (B,C): The $\mathrm{ZnO}-\mathrm{NPs}$ treated testicular sections showing Ps containing few aggregated mitochondria (curved arrow), ovoid shrinked nuclei (N) with some electron dense chromatic clumps (arrow) and disintegrated nuclear membrane (arrowhead). (D): The ZnO-NPs+ Nar treated testicular sections showing PS with large oval nucleus $(\mathrm{N})$ and some fine electron dense clumps of heterochromatin. Their cytoplasm has number of small aggregated mitochondria (curved arrow). (TEM x 1000x17) 

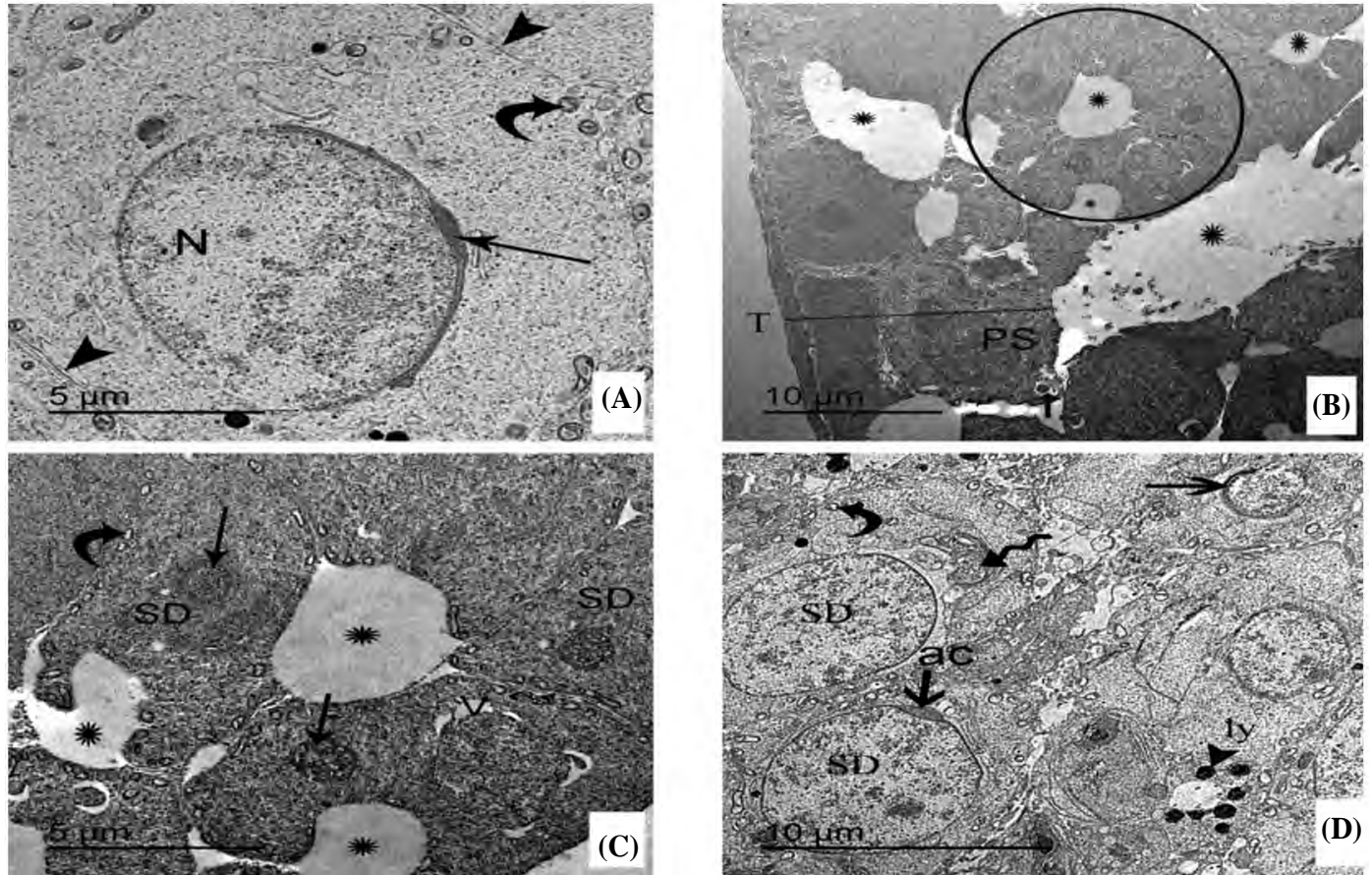

Fig. (6A-D): An electron micrograph of sections of adult albino rat testis. (A): The normal (control) rat testis showing the spermatid cells (sd) with well defined euchromatic nuclei $(\mathrm{N})$ surrounded by distinct nuclear membrane. The acrosomal cap (ac) appears spreading over the anterior hemisphere of their nuclei. The cytoplasm shows vacuolated peripheral mitochondria (curved arrow). Notice the tight junction between cells (arrowhead) is seen. (TEM x 1200x17) (B,C): The ZnO-NPs treated testicular sections showing multiple wide spaces between the cells $\left(^{*}\right)$ and areas of marked decrease in thickening of germinal layer (T). Notice the primary spermatocytes (PS) showing electron dense heterochromatic nucleus. (TEM x 500x17) (c): A higher magnification of (circle) of (Fig. B) showing Spermatids (SD) with electron dense shrunken nuclei and peripheral situated mitochondria (curved arrow). Electron lucent (v) vacuoles are seen inside their cytoplasm. (TEM x 1200x17) (D): The ZnO-NPs+ Nar treated testicular sections showing some spermatids (SD) with normal acrosomal cap (ac) or with normal gologi vesicle (zigzag arrow) and peripheral mitochondria (curved arrow). Other spermatids show abnormal acrosomal cap (arrow) or with many lysosomes (ly) in their cytoplasm. (TEM x 600x17).
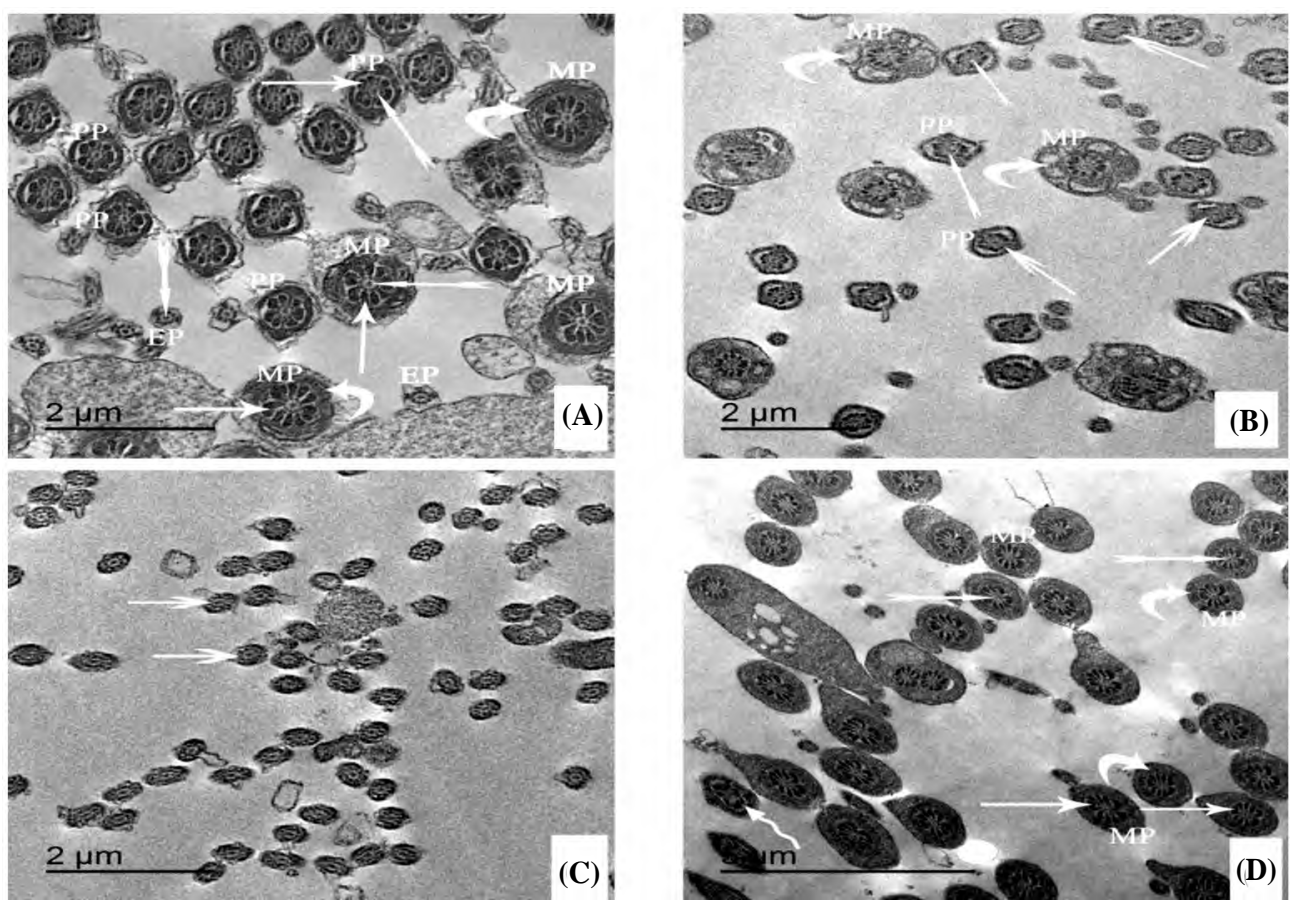

Fig. (7A-D): An electron micrograph of sections of adult albino rat testis showing cross sections in different pieces of the sperms. (A): Showing the middle piece of the sperm (MP) of normal (control) rat testis with core of central axoneme (notched arrow) surrounded by nine electron dense fibers (arrow) and outer less dense mitochondrial sheath (curved arrow). The principal piece (PP) is formed of axoneme (notched arrow) surrounded by seven outer dense fibers (arrow). Terminal end piece (EP) is formed of axoneme (notched arrow) surrounded by a cell membrane. (B,C): Showing ZnO-NPs treated testicular sections. (B): showing swelling and vacuolation (curved arrow) of mitochondrial sheath of middle pieces (MP) of the sperms. Notice ill defined axoneme (notched arrow) and hazy ill defined electron dense fiber (arrow) of middle piece (MP) and principal piece (PP). (C): SHowing markedly disorganized, distorted and degenerated sperms with invisible hazy central (arrow). (D): The ZnO-NPs and Nar treated testicular sections showing normal middle pieces (MP) of the sperms consisting of core of central axoneme (notched arrow) surrounded by nine outer dense fibers (arrow) and mitochondrial sheath (curved arrow). Some of sperms appear deformed and degenerated (zigzag arrow). (TEMx 2500x17). 

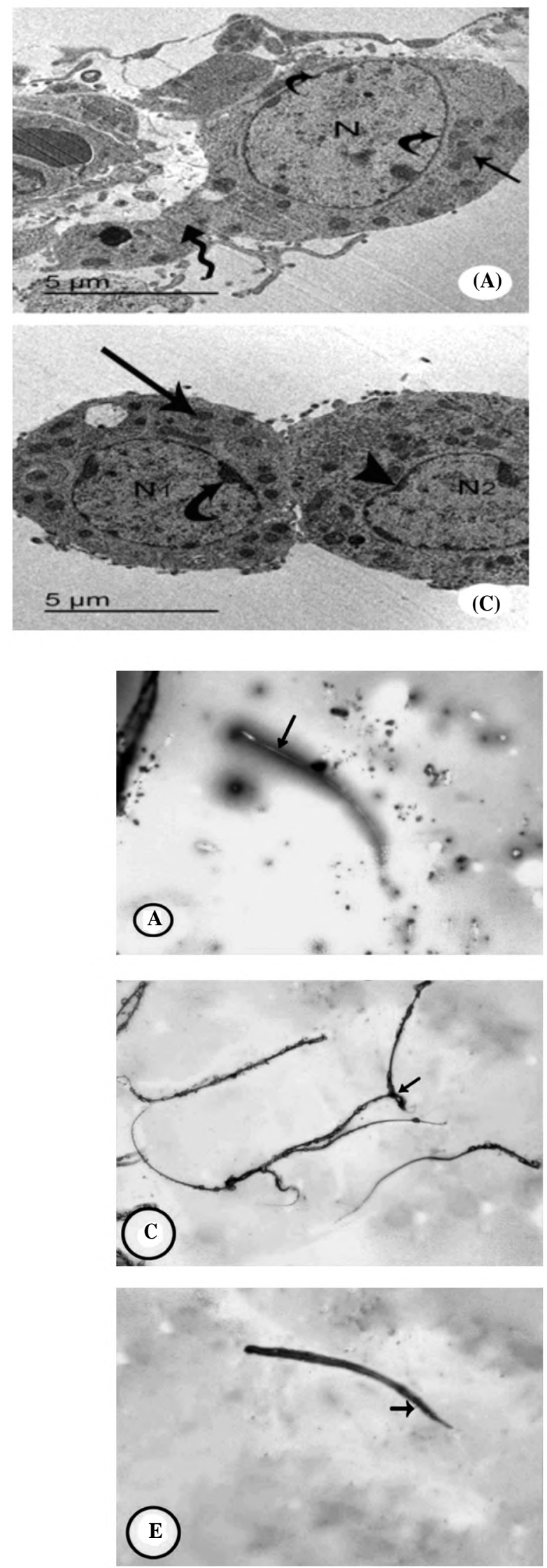

Fig. (9A-F): A photomicrograph of epididymal spermatozoa from adult male albino rats. (A): Control group showing normal rat sperm with normal constituents (Head, Neck, Tail) (arrow). (B-F): The ZnO-NPs treated group showing abnormal forms of sperm, with banana head (B), with coiled midpiece (C), with curved tail (D), with short tail (E) and with kinked neck (F). (EosinNigrosin x 400)

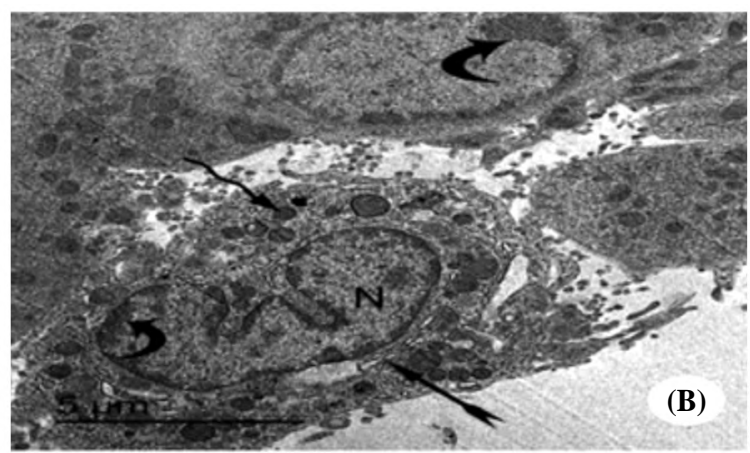

Fig. (8A-C): An electron micrograph of sections of adult albino rat testis showing the Leydig cells. (A): Showing the Leydig cells of normal (control) rat testis with large rounded euchromatic nuclei $(\mathrm{N})$ and thin marginated chromatin (curved arrow). It contains moderate number of mitochondria of variable size and density (arrow) and extensive cytoplasmic processes interdigitating with the neighboring ones (zigzag arrow).(B): The ZnO-NPs treated testicular section showing shrinked Leydig cells. It has highly indented nucleus $(\mathrm{N})$ with condensed marginated chromatin (curved arrow). It contains dilated rough endoplasmic reticulum (notched arrow), many electron dense mitochondria (zigzag arrow) (C): The ZnO-NPs and Naringenin testicular sections showing Leydig cells with large rounded euchromatic nuclei (N1) with thin marginated chromatin and few chromatic spots (curved arrow). Its cytoplasm contains moderate number of mitochondria of variable shape and size (arrow). While other leydig cell shows slight indented (arrowhead) nucleus (N2). (TEMx 2500x17.
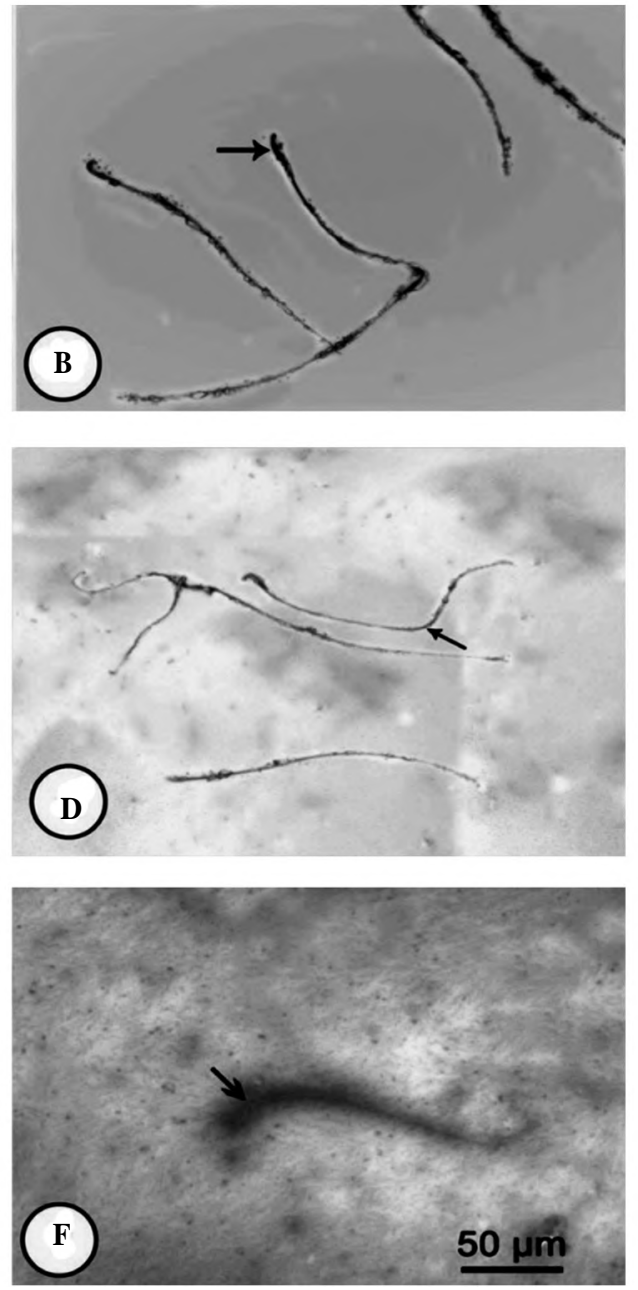


\section{Discussion}

Among different nanoparticles, Zinc oxide $(\mathrm{ZnO})$ occupies the most commonly used nanoparticles. It has wide applications ranged from personal care products, antibacterial creams, sensors and biomedical applications [19]. Their broad range of applications increases concern to their potential toxicity. So, it is required to study their toxicity.

The light microscopic examination of current study showed massive degenerative testicular changes in adult albino rats exposed to $700 \mathrm{mg}$ of $\mathrm{ZnO}-\mathrm{NPs}$. These changes were in the form of marked disorganization of seminiferous tubules, sloughing, depletion of germinal epithelium and pyknosis of spermatogenic cells. In accordance with the current results, Mozaffari et al., [10] revealed many testicular lesions such as increased number of degenerated and disorganized seminiferous tubules in $\mathrm{ZnO}-\mathrm{NPs}$ administrated group. Also these results are in agreement with Talebi et al., [20] who observed sloughing or even atrophy of epithelium of seminiferous tubules in rat received oral $300 \mathrm{mg} / \mathrm{kg} \mathrm{ZnO-NPs/day} \mathrm{for} 35$ days. ElMorshedi et al., [2] also observed testicular atrophy, degenerated seminiferous tubules and decline in spermatogenesis process after intramuscular injection by $200 \mathrm{mg} \mathrm{ZnO}$ nanoparticles/kg daily and $400 \mathrm{mg} \mathrm{ZnO}$ nanoparticles/kg daily.

Johnson [21] explained that sloughing of the germinal epithelium that involve portion or even encompass the whole circumference of the tubule may be due to toxic effect on Sertoli cell cytoskeleton. Erkanlı Şentürk et al., [22] reported that disruption in physical interaction between sertoli and other germ cells leading to sloughing and detachment of the germ cells. Halawa [23] added that nanoparticles had the ability to injury and even disrupt the basement membrane, germ cells and sertoli cells function leading to more elimination of injured cell by apoptosis. However, another study reported no obvious acute toxicity was detected in mice treated with intravenous injection of $30 \mathrm{mg} / \mathrm{kg}$ nanoparticles for 2 weeks [24]. Lee et al., [25] mentioned that wide variation in nanoparicles toxicity not only depends on size and dose but also route of administration and the duration of exposure of nanoparticles.

In the current study, statistical results of this work supported our previous histological findings. There was statistical significant decrease in the mean values of height of germinal epithelial layer and of the perimeter of seminiferous tubules in the treated groups if compared with control groups.
Talebi et al., [20] also reported that the diameters of the seminiferous tubules and height of the seminiferous epithelium were significantly decreased in both animals received 50 and $300 \mathrm{mg} / \mathrm{kg} \mathrm{ZnO}$ NPs/day for 35 days if compared with the control group.

In the present work, extensive deposition of hyaline acidophilic material in the interstitium with the presence of lipid droplets was also observed as previously reported by other author after intramuscular injection of rat by $400 \mathrm{mg} \mathrm{ZnO}$ nanoparticles/kg daily [2]

In the current study, electron microscopic examination in treated groups by $\mathrm{ZnO}-\mathrm{NPs}$, revealed also more cellular details confirming the toxic effect of zinc oxide nanoparticles. The results of this work have been shown that injury caused by $700 \mathrm{mg} \mathrm{ZnO-NPs} \mathrm{can} \mathrm{disrupt} \mathrm{intercellular} \mathrm{junctional}$ complexes which were seen between cells in the control group. This disruption was indicated by appearance of many marked intercellular gap spaces between spermatogenic cells or between the cells and the basement membrane in group II. These changes have been shown by ultrastructural study or by histological results of toluidine blue semithin sections of this work. This was also supported by previous findings by Gong et al., [26] who added that the dilated intercellular spaces and loss of contact between germ cells is apparently due to disturbances of Sertoli cell which lead to loss of the germ cells and finally to the destruction of testicular tissue and infertility.

The histological and ultrastructural results in treated group (II) of this study showed corrugation, thickening, detachment and separation of basement membrane of seminiferous tubules. This means that the basement membrane had altered structure and this may be associated with severe functional impairment of the testis. Makhlouf et al., [27] reported that this thickening may be due to increase in the amount of collagenous fibers in ST basement membrane and the number of myoid cells in the lamina propria of the ST. The amount of collagen fibers may be increased by two processes either due to an increased production of collagen fibers by fibroblasts or a decreased rate of collagen phagocytosis. Zheng et al., [28] added that during these pathological thickening processes, Sertoli cell functions were progressively altered and eventually suppressed. According to the disturbance progresses, the germ cells display a progressive arrest of the spermatogenetic processes. Subsequently, the basement membrane begins to separate, then thicken and finally shrunken. Further, the 
irregularities in the basement membrane, observed in the present study in Hematoxylin \& eosin and toluidine blue stains of group II, might be due to either tubular shrinkage or contraction of myoid cells as previously explained by Mohamed et al., [29] and Krishna et al., [30] .

In the present work, by light and electron microscopic examination, the damage of Sertoli cells was evident following administration of $700 \mathrm{mg}$ ZnO-NPs. The most characteristic features denoting degeneration of Sertoli cells, were cytoplasmic vacuolation and dilatation of smooth and rough endoplasmic reticulum. Ghadially [31] reported that lipid peroxidation is the main cause of accumulation of water inside the cell with resultant vacuoles formation and dilatation of cytoplasmic organelles as endoplasmic reticulum.

The vacuolation of sertoli cells was seen by toluidine blue semithin sections and ultrastructural results of this study in group II. The presence of vacuoles in the cytoplasm of the Sertoli cell denoted direct damage to this cell and reflected its early response to injury as indicated by the previous literature [32]. Wahbah et al., [33] explained these vacuolation due to the autophagosomes formed for the phagocytosis of necrotic germ cells by Sertoli cells. Another reason for the vacuolization of Sertoli cells may be due to swelling and coalescence of intracellular membrane-bound organelles like the ER [34]

In the current study, in group II, the spermatogonia and primary spermatocytes showed features of necrosis in the form of the presence of pyknotic nuclei characterized by chromatin condensation, shrinking or disintegration of nuclear membrane and rarefaction of cytoplasm with massive loss of most organelles. Thus, alterations of spermatogonia will be reflected on the development of the following stages of spermatogenesis. This might be either due to direct damage to these spermatogenic cells due to excessive production of reactive oxygen species (ROS) generated or secondary to the injury to the Sertoli cells as previously described by Krishna et al., [30].

Thakur et al., [35] assigned that Changes in the cellular nuclei, cytoplasm and shape are usually accompanied by function alteration of cell. The pyknosis is related mainly to cell necrosis. In addition, they defined pyknosis as altered shape of nuclei with resultant nuclear shrinkage and characterized by increased basophilia duo to DNA condensation into a shrunken mass. Creasy [36] added that any injury to Sertoli cells would affect the nutrition and sustenance of spermatogenic cells to their disintegration, subsequent necrosis, and their exfoliation into the lumen of the ST. Sertoli cells play an important role in spermatogenesis. Sertoli cells produce lactate, which is important for the survival of germ cell [34].

In the present work, many distorted spermatids were detected in treated group with ZnO NPs at different stages of differentiation in the form of shrinkage of their nuclei and vacuolation with accumulation of electron dense bodies in their cytoplasm. These degerative changes reflected the disturbance in the formation of the acrosome in the developing spermatid including the absence of the acrosomal cap, acrosomal vesicles or granules.

The present work, in treated groups also showed marked loss of spermatozoa, swelling and vacuolation of mitochondrial sheath of middle pieces of the sperms by light and electron microscopic examinations. Moreover, statistically, there were highly significant decrease in percentage $(\%)$ of motile sperms however, the percentage of abnormal sperm forms was highly significantly increased. These results were similar to the previous literatures $[20,30,32]$

\section{References}

1- JEEVANANDAM J., BARHOUM A., CHAN Y., DUFRESNE A. and DANQUAH M.K.: Review on nanoparticles and nanostructured materials history, sources, toxicity and regulations. Beilstein. J. Nanotechnol., 9: 1050-1074, 2018.

2- EL-MORSHEDI N., ZOHDY N., EL MULLA K., HASSAN M. and MORAD N.: Toxic Effect of Zinc Oxide Nanoparticles on Some Organs in Experimental Male Wistar Rats. International Journal of Advanced Research, 2 (4): 907-915, 2018.

3- KAO Y., CHEN Y., CHENG T., CHIUNG Y. and LIU P.: Zinc oxide nanoparticles interfere with zinc ion homeostasis to cause cytotoxicity. Toxicological Sciences, 125 (2): 462-472, 2011.

4- KHAN I., SAEED K. and KHAN I.: Nanoparticles: Properties, applications and toxicities. Arabian Journal of Chemistry, 2017.

5- JOHNSTON H.J. HUTCHISON G.R., CHRISTENSEN F.M. and READ S.: A review of the in vivo and in vitro toxicity of silver and gold particulates: Particle attributes and biological mechanisms responsible for the oserved toxicity. Critical Reviews in Toxicology, 40 (4): 328-346.

6- BAHADAR H., MAQBOOL F., NIAZ K. and ABDOLLAHI M.: Toxicity of nanoparticles and an overview of current experimental models. Iranian Biomedical Journal, 20 (1): 1, 2016. 
7- QUIDEAU S., DEFFIEUX D., DOUAT-CASASSUS C. and POUYSEGU L.: Plant polyphenols: Chemical properties, biological activities, and synthesis. Angewandte Chemie International Edition, 50 (3): 586-621, 2011.

8- PASHAEI R.: Features of Apigenin, Luteolin, Hesperetin and Naringenin in Crop and Body. Nutr. Diet., 5 (5): 3004, 2016.

9- CHANET A. MILENKOVIC D. MANACH C., MAZUR A. and MORAND C.: Citrus flavanones: What is their role in cardiovascular protection? Journal of Agricultural and Food Chemistry, 60 (36): 8809-8822, 2012.

10- MOZAFFARI Z., PARIVAR K., ROODBARI N.H. and IRANI S.: Histopathological evaluation of the toxic effects of zinc oxide $(\mathrm{ZnO})$ nanoparticles on testicular tissue of NMRI adult mice. Advanced Studies in Biology, 7: 275 291, 2015.

11-REDDY K.Y., SARITHA C., SRIDHAR Y. and SHANKARAIAH P.: Naringenin Prevents the Zinc Oxide Nanoparticles Induced Toxicity in Swiss Albino Mice. J. Pharmacol. Clin. Toxicol., 2 (1): 1021, 2014.

12- BANCROFT J.D. and GAMBLE M.: Theory and practice of histological techniques. Elsevier Health Sciences, 2008.

13- GLAURET A. and LEWIS P.: Biophysical, specimen preparation for transmission electron microscopy. Parhand Press, London, 17: pp. 1-50, 1998.

14- KIERNAN J.A.: Histological and histological methods. Theory and practice. 3rd edition, Oxford, Boston, Johannesburg and New Delhi, pp. 129-139, 2000.

15- BARTRA N., NEHRU B. and BASAL M.P.: Influence of lead and zinc on rat male reproduction at biochemical and histopathological level. J. Applied. Toxicology, 21: 507-512, 2001.

16- KLINEFELTER G.R., GRAY L.E. and SUARE J.D.: The method of sperm collection significantly influences sperm motion parameters following ethane dimethanesulphonate administration in the rat. Reprod. Toxicol., 5: 39-44, 1991.

17- TARDIF S., LAFOREST JP., COMIER N., et al.: The importance of porcine sperm parameters on fertility in vivo. Theriogenology, 52: 447-59.

18- MORI K., KAIDO M., FUJISHIRO K., INOUE N., KOIDE O., HORI H. and TANAKA I.: Dose dependent effects of inhaled ethylene oxide on spermatogenesis in rats. Br. J. Ind. Med., 48 (4): 270-274, 1991.

19- SINGH S.: Zinc oxide nanoparticles impacts: Cytotoxicity, genotoxicity, developmental toxicity, and neurotoxicity. Toxicology Mechanisms and Methods, 1-12, 2018.

20- TALEBI A.R., KHORSANDI L. and MORIDIAN M.: The effect of zinc oxide nanoparticles on mouse spermatogenesis. J. Assist. Reprod. Genet., 30 (9): p. 1203-9, 2013.

21- JOHNSON K.J.: Testicular histopathology associated with disruption of the Sertoli cell cytoskeleton. Spermatogenesis, 4 (2): 979106, 2014.

22- ERKANLı ŞENTÜRK G., EROSY CANILLIOGLU Y., UMAY C., DEMIRALP-EKSIOGLU E. and ERCAN F.: Distribution of Zonula Occludens-1 and Occludin and alterations of testicular morphology after in utero radiation and postnatal hyperthermia in rats. International Journal of Experimental Pathology, 93 (6): 438-449, 2012.

23- HALAWA A.M.: Effect of sildenafil administration on ischemia/reperfusion of the testis in adult Albino rat light and electron microscopic study. Egypt J. Histol., 33: 380395,2010 .

24- WANG B., FENG W., WANG M., WANG T., GU Y., ZHU M., OUYANG H., SHI J., ZHANG F. and ZHANG Y.: Acute toxicological impact of nano-and submicro-scaled zinc oxide powder on healthy adult mice. Journal of Nanoparticle Research, 10 (2): 263-276, 2008.

25- LEE J.H., KIM Y.S., SONG K.S., RYU H.R., SUNG J.H., PARK J., PARK H.M., SONG N.W., SHIN B.S. and Marshak D.: Biopersistence of silver nanoparticles in tissues from Sprague-Dawley rats. Particle and Fibre Toxicology, 10 (1): 36, 2013.

26- GONG Y., WU J., HUANG Y., SHEN S. and HANE X.: Nonylphenol induces apoptosis in rat testicular Sertoli cells via endoplasmic reticulum stress. Toxicology Letters, 186 (2): 84-95.

27- MAKHLOUF M., ELDIN M.S. and ZAGLOUL A.M.: The effect of lead acetate on testicular structure and protective effect of Vitamin $\mathrm{E}$ in adult albino rat. Egypt J. Histol., 31: 406-18, 2008.

28- ZHENG Y., ZHANG X., ZHOU J., CHENG F., RAO T and Yao Y.: The effects of artery-ligating and artery preserving varicocelectomy on the ipsilateral testes in rats. Urology, 72: 1179-84, 2008.

29- MOHAMED D., SABER A., OMAR A. and SOLIMAN A.: Effect of cadmium on the testes of adult albino rats and the ameliorating effect of zinc and vitamin E. British. J. of Science, 11: 72-95, 2014.

30- KRISHNA H., CHANGIL A., SRINIVAS M., ROY T.S and JACOB T.G.: Ultrastructural study of rat testis following conventional phototherapy during neonatal period. J. Microsc. Ultrastruct, 6: 205-211, 2018.

31- GHADIALLY F.N.: Ultrastructural pathology of the cell and matrix: a text and atlas of physiological and pathological alterations in the fine structure of cellular and extracellular components. Butterworth-Heinemann, 2013.

32- EL SHAFAI A., ZOHDY N., EL MULLA K., HASSAN M. and MORAD N.: Light and electron microscopic study of the toxic effect of prolonged lead exposure on the seminiferous tubules of albino rats and the possible protective effect of ascorbic acid. Food and Chemical Toxicology, 49 (4): 734-743, 2011.

33- WAHBAH N.S., EL FATTAH E.A., AHMED F.E. and HASSAN E.Z.: Histological study of the effect of exogenous glucocorticoids on the testis of prepubertal albino rat. Egypt J. Histol., 33: 353-64, 2010.

34- HILD S.A., REEL J.R., DYKSTRA M.J., MANN P.C. and MARSHALL G.R.: Acute adverse effects of the indenopyridine CDB 4022 on the ultrastructure of Sertoli cells, spermatocytes, and spermatids in rat testes: Comparison to the known Sertoli cell toxicant di n pentylphthalate (DPP). J. Androl., 28: 621-9, 2007.

35- THAKUR M., GUPTA H., SINGH D., MOHANTY I., MAHESWARI U., VANAGE G. and JOSHI D.: Histopathological and ultra structural effects of nanoparticles on rat testis following 90 days (Chronic study) of repeated 
oral administration. Journal of Nanobiotechnology, 12 (1): 42, 2014

36- CREASY D.M.: Pathogenesis of male reproductive toxicity. Toxicologic Pathology, 29: 64-76.

37- RENGAN A.K., AGARWAL A., VANDERLINDE M and DUPLESSIS S.: An investigation of excess residual cytoplasm in human spermatozoa and its distinction from the cytoplasmic droplet. Reproductive Biology and Endocrinology, 10 (1): p. 92, 2012.

38- GOUDA Z.A. and SELIM A.O.: A possible correlation between the testicular structure and short photoperiod exposure in young albino rats: Light and electron micro- scopic study. Egyptian Journal of Histology, 36 (1): 2838, 2013.

39- PROCHÁZKOVÁ D., BOUS`OVÁ I. and WILHELMOVÁ N.: Antioxidant and prooxidant properties of flavonoids. Fitoterapia, 82 (4): 513-523, 2011

40- PATEL K., SINGH G.K. and PATEL D.K.: A review on pharmacological and analytical aspects of naringenin. Chinese Journal of Integrative Medicine, 24 (7): 551-560, 2018.

41- LIM K.H. and KIM G.R.: Inhibitory effect of naringenin on LPS-induced skin senescence by SIRT1 regulation in HDFs. Biomedical Dermatology, 2 (1): 26, 2018.

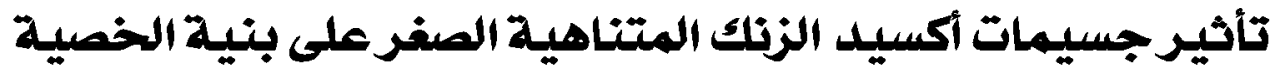

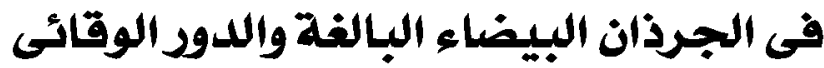 المحتمل للنارنجنين}

مقدمة: تستخدم جسيمات أكسيد الزنك النانونية كمصدر للزنك فى صناعة المواد الغذائية ففى مستحضرات التجميل وإكن تراكمها بكمية

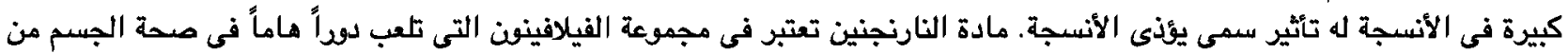

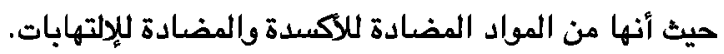

الغرض من البحث:والهدف من هذه الدراسة هو تقييم التغيرات الهيكلية التى تصدث فى أنسجة الخصية الجرذان البيضاء البالغة من تأثير حقن جسيمات أكسيد الزنك النانونية بجرعة واحدة من خلال الغشاء الصفاقى وتوضيح الدود الوقائى المحتمل لمادة النارنجنين ضد هذه النيات السمية.

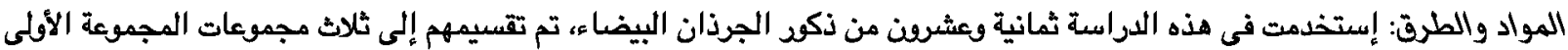

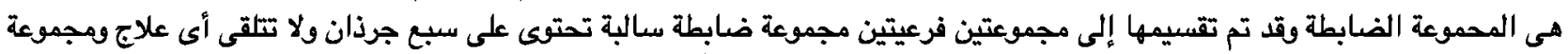

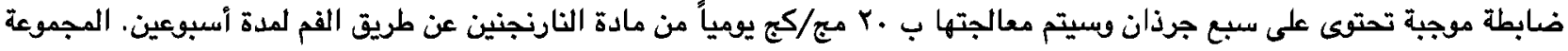

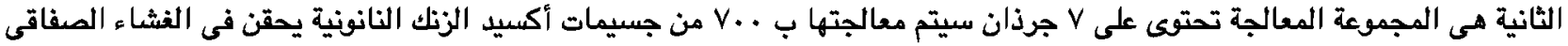

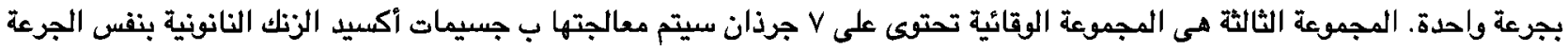

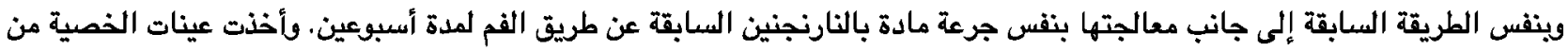

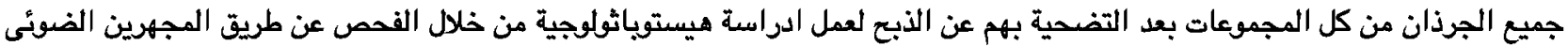

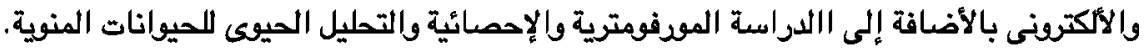

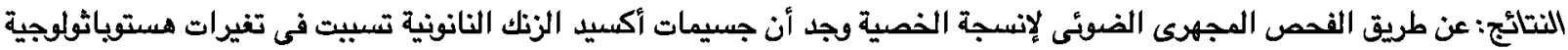

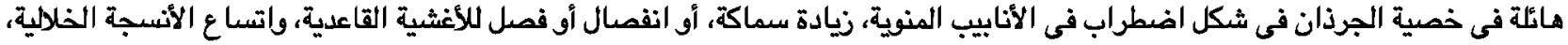

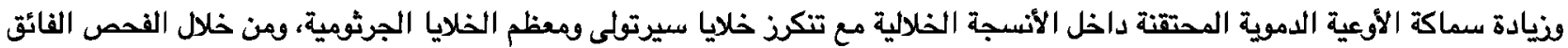

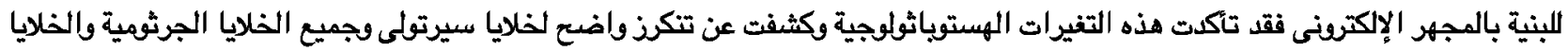

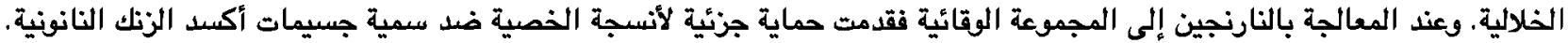
ومن خلال التحليل الإحصائى فقد تاكدت كل هذه النتائج السابقة. الاستتاج: لقد وجد أن جزيئات أكسيد الزنكل يمكن أن يؤدى إلى مخاطر على الهيكل النسيجى اللضصيتين فلكن المعالجة بالنارنجين قامت 